\title{
Suspension of insurers' dividends as a response to the COVID-19 crisis: evidence from the European insurance equity market
}

\author{
Petr Jakubik $^{1}$ D Saida Teleu ${ }^{1}$
}

Received: 1 January 2021 / Accepted: 29 July 2021 / Published online: 4 October 2021

(c) The Geneva Association 2021

\begin{abstract}
The recent COVID-19 outbreak and significant increase in resulting global uncertainty poses many challenges to financial sectors. Many regulators took measures to safeguard the resilience of financial institutions by requesting postponements of dividend distributions until uncertainties about further development diminished. Specifically, on 2 April 2020, the European Insurance and Occupational Pensions Authority issued a statement requesting that re/insurers suspend all discretionary dividend distributions and share buybacks aimed at remunerating shareholders. Although the goal was to strengthen the overall financial stability of the sector, it may have negatively influenced insurers' equity prices in the short term. Hence, this paper empirically investigates this potential effect using an event study methodology. Although negative drops were observed in some cases, the obtained empirical results suggest that they were not statistically significant for the European insurers' equity market when considering the event windows covering several days after the statement was published.
\end{abstract}

Keywords European insurance sector - Suspension of dividend distributions · Event study $\cdot$ EIOPA statement $\cdot$ Equity market

\section{Introduction}

Although the COVID-19 crisis did not originate in financial sectors, unlike the financial crisis of 2007-2008, financial institutions were significantly affected by an unprecedented shock to financial assets and subsequent lockdowns of many

Petr Jakubik

jakubik@fsv.cuni.cz; petrjakubik@seznam.cz

Saida Teleu

saida.teleu@fsv.cuni.cz; teleusaida@gmail.com

1 Institute of Economic Studies, Faculty of Social Sciences, Charles University in Prague,

Opletalova 26, 11000 Prague, Czech Republic 
economies. In addition, risk-free rates were compressed for all maturities as a response to expected lower economic growth and further continuation of accommodative monetary policies. This paper focuses on negative impacts to European insurance companies from drops in the market value of their assets as well as increases in the value of their liabilities driven by lower discount rates following the COVID-19 outbreak.

The insurance sector's financial stability is essential to ensuring access to and continuity of insurance services, safeguarding the ability of the sector to continue to perform its role as a risk transfer mechanism from citizens and businesses, as well as its capacity to mobilise savings and invest them in the real economy. This objective requires that re/insurers take all necessary steps to continue to ensure a robust level of their own funds in order to fulfil obligations to policyholders and absorb potential losses. In the wake of the coronavirus outbreak, safeguarding the stability of the sector is relevant not only from a business continuity perspective, but also from a forward-looking perspective, as the sector might play a key role in supporting economic recovery via long-term investments. To this end, following the COVID-19 outbreak, the European Insurance and Occupational Pensions Authority (EIOPA) ${ }^{1}$ urged insurance companies to halt dividends, share buybacks and bonuses. In its statement issued on 2 April 2020, ${ }^{2}$ EIOPA indicated that insurance companies must take all necessary steps to continue to ensure a robust level of their own funds so as to protect policyholders and absorb potential losses. Against this background of uncertainty, EIOPA urged that, during the pandemic, re/insurers should temporarily suspend all discretionary dividend distributions and share buybacks aimed at remunerating shareholders. In addition, national supervisory authorities issued their own statements, which were broadly in line with that from EIOPA, with the exception of the German Supervisory Authority (BaFin). As a response to the EIOPA and national statements on dividend distributions, insurers made their own announcements, which were not always in line with the recommendations of supervisory authorities. This is because EIOPA and many national supervisory authorities do not have the legal power to force insurers to follow their guidelines.

As a result of the COVID-19 pandemic, insurance companies' equities have fallen sharply (Liedtke 2021). Apart from the potential for large claims, investors have been concerned about the impact of the economic slowdown on the investment portfolios insurers hold against their liabilities. The EIOPA statement on restricting dividend distributions had the potential to negatively affect insurers' share prices further, as some investors may have held insurance companies' equities largely for their payouts rather than capital gains, which are quite low in the current low-yield

\footnotetext{
1 EIOPA is a European Union financial regulatory institution established under EU Regulation 1094/2010. EIOPA is one of the three European Supervisory Authorities responsible for microprudential oversight of re/insurance and occupation pension sectors at the European Union level, being part of the European System of Financial Supervision. EIOPA's core responsibilities are to support the stability of the financial system, transparency of markets and financial products, as well as the protection of insurance policyholders, pension scheme members and beneficiaries.

${ }^{2}$ See https://www.eiopa.europa.eu/sites/default/files/publications/statement-on-dividend-distributi on-april2020.pdf.
} 
environment. Although the statement aimed only at the postponement of dividend distributions until the situation in the market stabilised, the negative effect could stem from a discounting effect associated with the postponement of potentially the same sum of future cash flows. In addition, investors might worry that insurers are considered a tool of economic policy and should be managed in order to provide positive externalities. Conversely, because the statement forced capital reinforcement in bad times, it may have helped companies to weather the COVID-19 crisis more easily. In this respect, equity prices could even react positively.

In this paper, we provide an empirical assessment of potential drops in share prices as a response to the published EIOPA statement, also taking into account announcements made by national supervisory authorities and insurance companies. We employ an event study framework to statistically test whether any potential drops in equity prices are statistically significant. The paper is organised as follows. First, we present the literature related to this study and form the tested hypothesis. Second, we describe the data and methodology used. Third, we provide the results of our empirical analysis. The last section concludes based on the obtained results.

\section{Literature review}

Several theoretical models and empirical studies in the literature address various dividend-related issues. Two schools of thought are particularly noteworthy: dividend irrelevance and dividend relevance. These theories assess the change in a firm's value caused by its dividend policy. According to Modigliani and Miller's (1959) Dividend Irrelevance hypothesis, the dividend decision should be a matter of indifference to the shareholders in an efficient market. This hypothesis was examined and supported by Black and Scholes (1974) through the assessment of stock returns and dividend yield relationship, suggesting that stock prices do not affect a firm's dividend policy. Conversely, there is an extensive literature documenting how investor irrationality, limits of arbitrage and market inefficiencies render the dividend policy relevant to a firm's valuation. Economic theory suggests that the management of a firm may use dividend changes to overcome information asymmetries by signalling revisions to earnings expectations to existing and prospective investors (e.g. Lintner 1956; Akhigbe et al. 1993). This is the so-called signalling hypothesis of a dividend policy, intended to explain the existence of dividend payments. However, many financial economists observe that firms attempt to avoid dividend cuts that are presumed to provide information perceived to be negative by external economic agents.

The majority of the literature discusses dividend policy from the perspective of individual firms. Only a few researchers have focused on regulating earnings distributions under certain conditions with respect to insurance firms. Lee and Forbes (1980) examine the U.S. property and liability insurance industry using the monthly returns of 34 insurance stocks and their dividend payouts. They find some empirical evidence suggesting that dividend policy affects the stock prices of insurance companies. Akhigbe et al. (1993) further refined the results of Lee and Forbes (1980) using cross-sectional event studies to compare the stock price response to dividend 
increases. Their results indicate that the dividend changes of insurance firms are perceived differently from those of industrial firms. Furthermore, they find that the response of life insurers' stock prices to dividend changes was less pronounced, conveying less asymmetric information than those of other insurers. This indicates that shareholders may be interested in sensitive information about future cash flows, and dividend signalling may have particular importance in the non-life insurance industry. Following the emergency fund theory and unemployment, the life insurance sector is more vulnerable to the macroeconomic environment due to the deteriorating economic conditions of individuals (The Geneva Association 2012).

The literature on insurance insolvency in relation to the macroeconomic environment, risk appetite and portfolio choices suggests that equities of both life and nonlife insurance companies fluctuate with the macroeconomic environment (Browne et al. 1999; Kim 2005; EIOPA 2018), and economic and market conditions affect investor and shareholder reactions to identical events (Gallo et al. 2016; Gupta et al. 2019). Docking and Koch (2005) find increased volatility of dividends in response to changes in dividend payment patterns when those changes did not reflect market development. Furthermore, a dividend payout restriction from a macroprudential perspective can also make the policy prone to opposition and criticism due to time inconsistencies and distribution effects (Brunnermeier et al. 2009). This lack of complete information may increase the problems with information asymmetries. As a result, shareholders may have a special interest in non-publicly available or additional information about future cash flows. Following this hypothesis, dividend signalling would quite clearly play a significant role for insurance firms. In this regard, Akhigbe et al. (1993) note that regulators could force life insurers to disclose more information to the public, in comparison to industrial firms, in order to reduce the importance of dividend signalling.

Insurers are often regarded as unique in that they are highly dependent on the financial soundness of the overall insurance sector of a country. Therefore, the insurance industry in the EU and other parts of the world is subject to very tight financial regulation. In this respect, insurance regulators primarily aim to guarantee the solvency of insurance firms. Based on analyses of the dividend policy of U.S. life insurers, Harrington (1981) argues that high dividend payouts can weaken the financial soundness of insurance companies. His findings indicate that the dividend policy of U.S. insurance companies overall reacts rather slowly to changes in firm earnings. In general, the resolution of an insurance company is three to five times more expensive than that of other financial institutions (Grace et al. 2003), which justifies its highly regulated environment. Hence, investors prefer a high degree of leverage in the insurance sector because shareholders as well as customers are protected against insolvency by regulators (Lee and Forbes 1980; Casey et al. 2007). This means that shareholders can use dividend income from insurers to obtain other financial assets, simultaneously maintain a constant amount of funds in their portfolio of insurance stocks and a higher level of relatively risk-free leverage.

From the agency theory perspective, proposed by Jenden and Meckling (1976), diverting the company's free cash flow from shareholders' private benefits might be perceived as expropriation (La Porta et al. 1998; Faccio et al. 2001). In this regard, examining U.S. data, Rozeff (1982) suggests that the special status of regulated 
firms might affect dividend policy. Casey et al. (2009) employ an extended version of Rozeff's model, suggesting that insurers do not require strong external monitoring as this function is carried out by regulators. Hence, agency costs are not a major factor in highly regulated markets. Observers of the banking industry suggest that the monitoring function cannot be supported during the capital shortage and new equity issues in the financial industry, and thus Reddmen et al. (2010) question the validity of the agency theory.

According to the 84th BIS Annual Report (2014) and Shin (2016), the majority of banks in the EU failed to maintain an adequate capital level via retained earnings due to the relatively high reluctance to suspend dividend payouts. This suggests that companies tend to smooth dividends over the cycle (e.g. Lintner 1956; DeAngelo et al. 2009) and attempt to avoid costly external finance (Almeida et al. 2004; Leary and Michaely 2011). Similarly, Abreu and Gulamhussen (2013) analyse dividend payouts of U.S. bank holding companies during the global financial crisis and find that the agency cost hypothesis does explain dividend payouts, particularly before and during the financial crisis, and that companies tend to pay more dividends to accommodate the increased need to monitor. David and Ginglinger (2016) explore payout channel choices via the agency theory and find that firms with significant institutional investors are quicker to pay out dividends in an economic downturn in order to maintain confidence in the market.

Literature related to dividend payment cuts and the desirability of regulating earnings distribution has gained momentum in light of the 2008-2009 financial crisis and the COVID-19 global economic downturn. Based on U.S. banking data for the financial crisis period of 2007-2009, Acharya et al. (2012) advocate dividend restrictions and capital conservation. Similarly, Admati et al. (2013) suggest the imposition of regulatory sanctions in bad times. Goodhart et al. (2010) and Acharya et al. (2017) provide a theoretical rationale for implementing dividend payout restrictions for banks in times of crisis, highlighting that this measure is beneficial for both debt and equity holders.

Based on data from the European Monetary Union (EMU) as a whole, Germany and Italy, Reddemann et al. (2010) analyse the dividend policy of the European insurance industry. They find no clear empirical evidence to suggest that dividend smoothing or dividend signalling are relevant economic phenomena for Germany and the EMU. Their finding suggests that insurers may cut dividends to strengthen financial stability during a crisis without necessarily having to fear adverse consequences of investors, assuming the measure is a clear sign of future problems. Conversely, insurers in Italy were more concerned that shareholders could interpret a suspension of dividend payouts as a sign of future trouble. Hence, this indicates that dividend smoothing is a relevant economic phenomenon for the Italian insurance sector.

While a small number of studies does exist, empirical research efforts to analyse the dividend policy of insurance companies from a regulatory perspective have been quite limited. Indeed, the majority of financial economists believe that additional empirical evidence is needed (Reddemann et al. 2010; Jeong 2013, among others). This paper contributes to the growing literature on regulating earnings distribution advised by insurance regulators. The relevant literature suggests that the 
agency theory may not hold for highly regulated financial firms because strong external monitoring is carried out by regulators, particularly in times of crisis (Casey et al. 2009; Reddemann et al. 2010). Moreover, as discussed above, some research advocates are in favour of regulatory restriction in bad times (Acharya et al. 2012; Admati et al. 2013; Goodhart et al. 2010). We test the null hypothesis that the EIOPA statement did not have a statistically significant, negative impact on European insurers' equity prices. This hypothesis is in line with the conclusions available in the existing literature as well as the arguments provided in the introduction of this paper. Furthermore, it would support the topic, currently widely discussed by policymakers, that restrictions on dividend distributions could be used as a macroprudential measure to help reduce uncertainty about potential inadequate solvency positions in times of crisis. The introduction of such a measure consistently across the whole sector could help to avoid any potential stigma effect that might arise in the event of individual decisions at the company level. Some research suggests that the efficiency of central bank communication in relation to financial stability was reduced during the financial crisis of 2007-2008 due to the long period required to align participants' actions to the direction imposed by the central bank (Tomuleasa 2015). Hence, quick and coordinated action preserving firms' capital may well capture rising uncertainties so as to avoid any potential stigma problems.

Despite the extensive literature on the determinants and effects of payout policies, to our knowledge, this is the first study to evaluate the effect of the dividend-based prudential regulation of a European insurance regulator (EIOPA) in complementing existing solvency regulation to improve the soundness and financial stability of the insurance sector. Moreover, in contrast to the banking sector, dividend payout restrictions in the insurance sector are a relatively new topic.

\section{Data description and methodology}

We assess the potential impact of the EIOPA statement via an event study, which measures the impact of an economic event, such as a statement on dividend distribution, on equity prices by using financial market data. To this end, we follow the event study methodology described by Brown and Warner (1985), Thompson (1995) and MacKinlay (1997). Furthermore, we employ the Boehmer, Mucumeci and Poulsen (BMP) test, which is also known as the standardised cross-sectional test (Boehmer et al. 1991). However, when a specific event shows a slight cross-correlation, the test statistics reject the null hypothesis too often when this hypothesis is true (Kolari and Pynnönen 2010). Hence, we address the issue of cross-sectional correlation in event studies with partially overlapping event windows by following the approach of Kolari and Pynnonen (2010). Given that the considered event window for testing the impact of the EIOPA statement is identical for all companies, we use the Adjusted Boehmer, Mucumeci and Poulsen (Adj-BMP) test, which provides a more robust test statistic (Kolari and Pynnönen 2010). This test takes cross-correlation and inflation of event-date variance into account in improving the power of test statistics. Apart from the above parametric methods, we use a non-parametric rank test proposed by Corrado and Zivney (1992) as a robustness check. 
The investigated event occurred on the evening of 2 April 2020 after the market close. Hence, the event day is denoted as 3 April. Given the rationality in equity markets, the effects of an event should be reflected in the observed security prices, and a measure of the event's economic impact can be constructed using equity prices collected over a relatively short period. Therefore, the event window is set up from Thursday, 2 April, denoted as $T_{1}$, to Tuesday, 14 April 2020, denoted as $T_{2}$, corresponding to seven working days - one day before the event and five days after. In this way, we also include the first working day after the Easter holiday.

The impact of the EIOPA statement was tested for equity prices of 33 European re/insurers listed via the described methodology. In order to measure market return, we employ the STOXX Europe 600 Index. Additionally, we use daily data for insurance companies for the period prior to the event window to calculate expected returns. Specifically, we use the period from the beginning of 2017 until 1 April 2020, which is denoted as $\left[T_{0}, T_{1}-1\right]$.

Simple descriptive statistics show that negative abnormal returns were observed in most cases (for almost 85\% of the sample) on Friday, 3 April 2020 after publication of the statement, with an average value of $-3.23 \%$. However, many of these daily negative abnormal returns were recovered by positive abnormal returns in two subsequent working days after the weekend, with average values of $0.67 \%$ and $2.55 \%$, respectively (see Table 1 ). The positive trend in market performance changed again on Wednesday, 8 April, with an average negative return of $1.08 \%$. However, these losses were fully recovered on Thursday, 9 April before the Easter holiday. The negative return was then recorded on the first working day after the holiday, Tuesday, 14 April, with an average market drop of $2.11 \%$.

The event-day negative return followed by the positive return on the subsequent two days seems to suggest an initial over reaction followed by market participants' gradual adjustment to the situation. This development may suggest that investors were not sure about the overall implications, as well as to what extent National Supervisory Authorities (NSAs) and insurers would implement the statement. Moreover, there could be different types of investors with different motivations and corresponding investment strategies. Some investors with rather speculative motives might focus on short-term profits; others might belong to long-term institutional investors, such as pension funds. Those investors may be able to step in to take over the shares sold by speculators. This is also in line with the existing literature claiming that investors prefer a high degree of leverage in the insurance sector because it is highly regulated to protect insurers against insolvency (Lee and Forbes 1980; Casey et al. 2007). Hence, there could by some convergence process characterised by increased volatility of insurers' equity prices.

To better assess the impact of the EIOPA statement issued on 2 April, we also need to consider the relevant communications of NSAs, which might be reflected in equity market development. Some NSAs had issued their own statements before the one issued by EIOPA. This was the case for the NSAs from Switzerland (25 March), Norway (16 March), Italy (30 March) and the U.K. (31 March), which complied to a certain extent with the EIOPA statement. However, the degree of alignment with the EIOPA statement differed. The U.K. regulator (PRA), which is no longer a member of EIOPA after Brexit, urged insurers to pay close attention to the need 


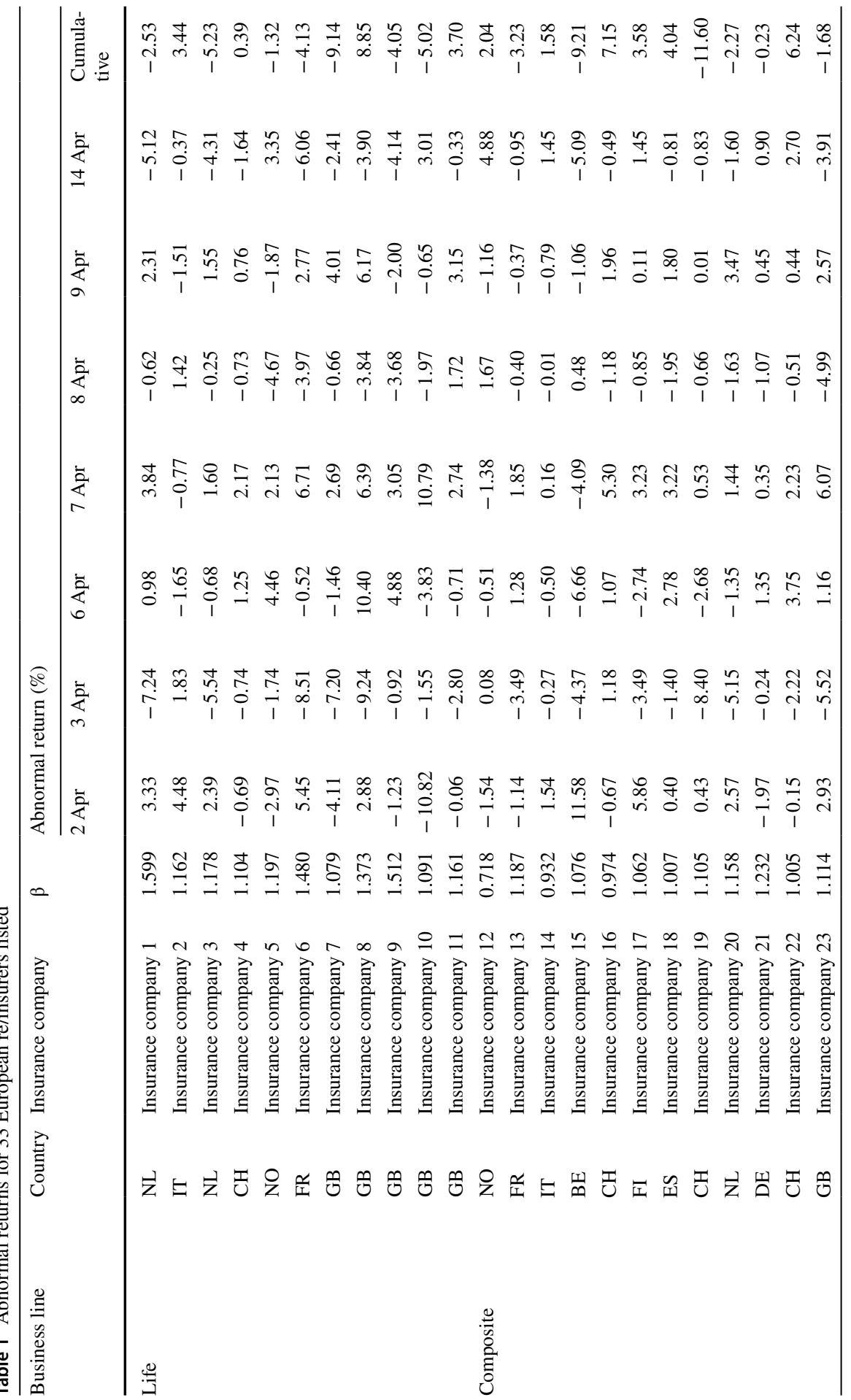




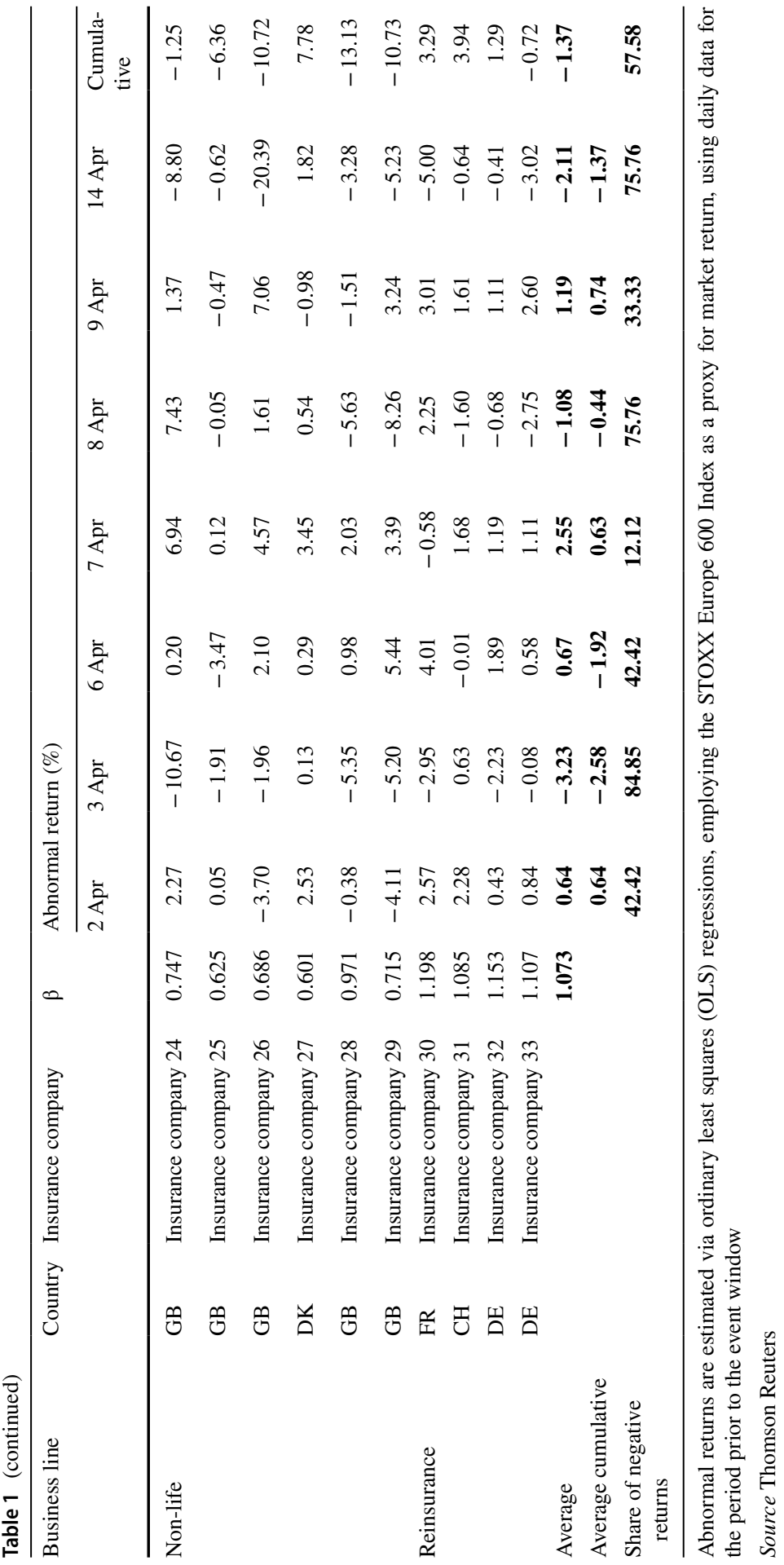


to protect policyholders when making decisions on shareholder payouts and staff bonuses in 2020, but did not directly force the cancellation of existing or future dividends. Similarly, the Italian supervisory authority (IVASS) sent a letter to insurance and reinsurance companies with head offices in Italy requesting them to use extreme caution, at solo and group levels, in the distribution of dividends and in the payment of the variable remuneration component of key managers. IVASS also emphasised close monitoring of compliance with these recommendations. The Norwegian regulator (Finanstilsynet) expected companies' boards of directors to review the distribution of profits for the 2019 financial year in light of the crisis and economic uncertainty. Based on their review, Finanstilsynet also expected the boards of directors, if necessary, to submit new proposals to the companies' general meeting on dividend payments and other payouts. Finally, the Swiss regulator (FINMA), which is not a member of EIOPA, explicitly welcomed the decision of all Swiss financial institutions to suspend their share buyback programmes.

Hence, in the cases described, the EIOPA statement might not have had a significant impact as market prices might have already contained potential effects. Moreover, as a response to the EIOPA statement, the German Federal Financial Supervisory Authority (BaFin) announced that it did not consider a blanket ban on distributions by insurance companies necessary, but that the dividend policy had to take into account the individual situation of insurers. Hence, we also compose a 'reduced sample' for which, compared to the 'full sample', insurers from Switzerland, Italy, Norway, the U.K. and Germany, are excluded. Additionally, Switzerland and the U.K. are not EIOPA members and so full responsibility lies only with the Swiss Financial Market Supervisory Authority (FINMA) and the Bank of England, which prudentially regulates and supervises financial services firms through the Prudential Regulation Authority (PRA). Moreover, as many NSAs do not have direct legal power or did not strictly ban dividends, we also have to analyse communications at the insurance company level. In this respect, Italian and Swiss insurers in the sample paid out dividends. ${ }^{3}$ This was also the case for three of six, and one of two insurance companies in the sample from the U.K. and Norway, respectively. All German insurers in the sample maintained the payment of dividends and a share buyback. Furthermore, even for those countries where NSAs strongly supported the EIOPA statement, some insurers still paid out dividends. This was the case for one Spanish insurer ${ }^{4}$ and one French insurer. ${ }^{5}$ Considering individual announcements at the insurance company level, we further exclude the mentioned French insurer (insurance company 13) from the 'reduced sample' as the announcement to pay dividends was made within the considered event windows. Conversely, the announcement of the mentioned Spanish insurer (insurance company 18) occurred at the end of April, i.e. outside of the event window, and therefore should not have any impact on the equity prices in the timeframe considered. To obtain a complete picture, we

\footnotetext{
3 The Board of Directors of insurance company 14 confirmed the proposal to distribute dividends, but to divide it into two tranches.

${ }^{4}$ On 30 April, insurance company 18 announced it would pay dividends on 25 June 2020.

5 On 3 April, insurance company 13 announced that the draft resolutions to pay a dividend remained unchanged.
} 
also conduct an empirical analysis for a 'residual sample', which contains all insurers from the full sample that are not included in the reduced sample.

The full list of announcements and corresponding days at the national and company levels is provided in Table 2 .

\section{Empirical results}

We employ the described methodological framework to empirically test the impact of the EIOPA statement on insurers' equity prices. We check the significance of abnormal return changes for a single day window [see the Appendix, Formula (5)].

The obtained numbers for the test statistics suggest a significant drop in equity prices on 3 April, on the first day after the publication of the statement, and further on the sixth day after the publication. Conversely, the test statistics indicate a significant positive development in insurers' equity prices on the third and fifth days after the publication for both samples (see Table 3). Contrary to the reduced sample, the full and residual samples show a significant decrease and increase in prices on the fourth and the second day after the publication, respectively.

We further statistically test whether the negative drops are not compensated by subsequent increases using the concept of average cumulative abnormal return [see the "Appendix", Formula (3)] for different event windows from days 1 to 7 (2-14 April). ${ }^{6}$

The empirical results for the full and residual samples reveal that the negative drop in equity prices after the publication of the statement was significant only when considering the event window up to two days after the event (see Table 4). For the event windows starting from 2 April and ending from three to seven days after the publication, the null hypothesis could not be rejected for the full and residual samples. Moreover, for the reduced sample, the null hypothesis could not be rejected for any of the considered event windows. This suggests that there was no statistically significant drop in equity prices after the publication of the statement.

However, as the cross-sectional test used could have a lower power, we further employ a standardised cross-sectional test [BMP test—see the "Appendix", Formula (7)].

Although the significance for the BMP test slightly decreases compared to the previous results, it does not change the main conclusion (Table 5). Furthermore, as this event study contains only one identical event window for all insurance companies included in the sample, a BMP-adjusted test [see the "Appendix", Formula (12)] is used to address cross-sectional correlation (Kolari and Pynnonen 2010).

The BMP-adjusted test further confirms our conclusion (Table 6). Moreover, the non-parametric rank test using test statistics [see the "Appendix", Formula (14)] was employed as a robustness check (Cambel and Wasley 1993) (Table 7).

When interpreting the results, we have to take into account the general market sentiment of investors on the days around the announcement. Stock markets had

\footnotetext{
${ }^{6}$ 4, 5, 11 and 12 April 2020 correspond to weekends; 10 and 13 April correspond with the Easter holidays.
} 


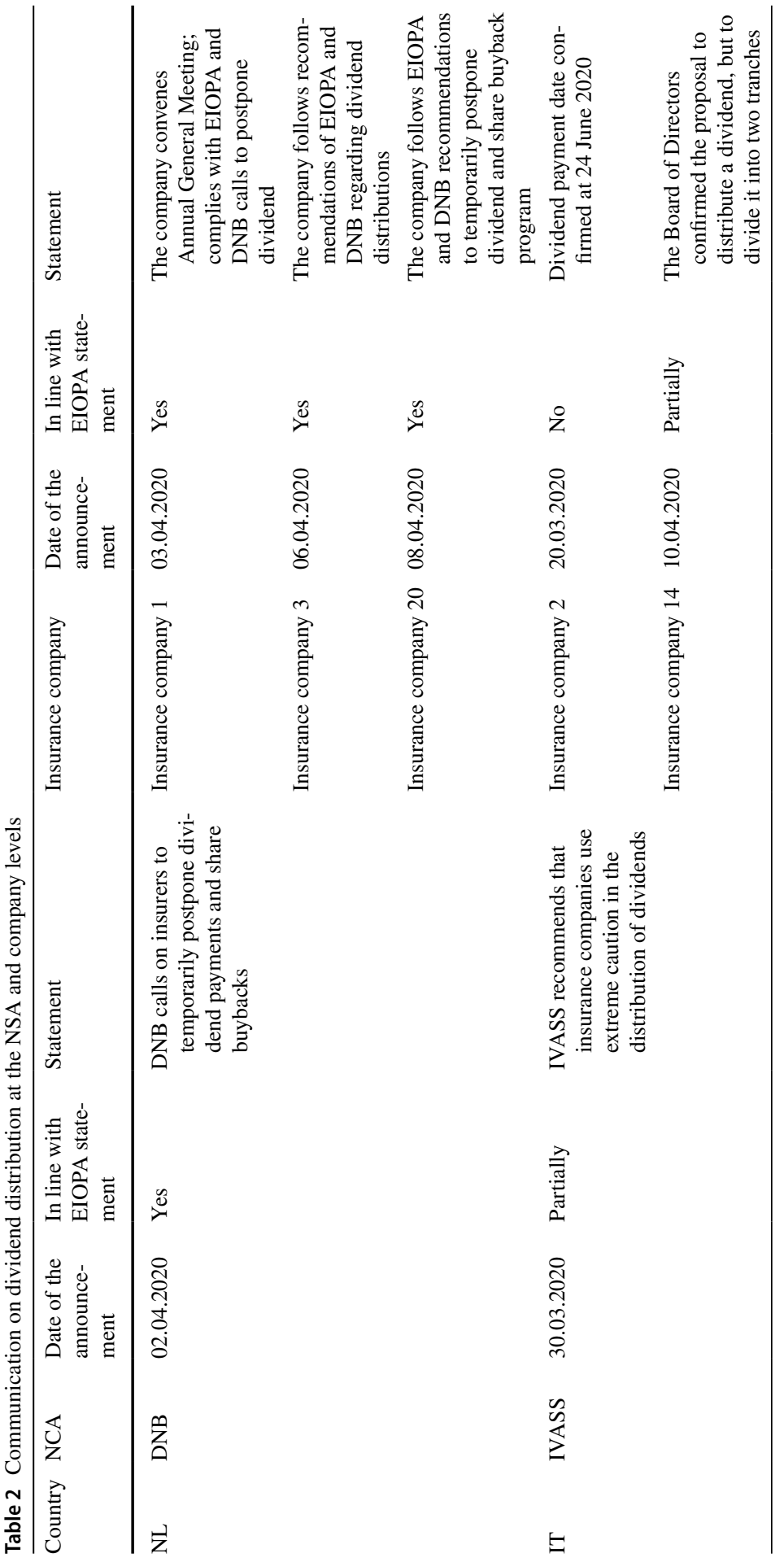

站 


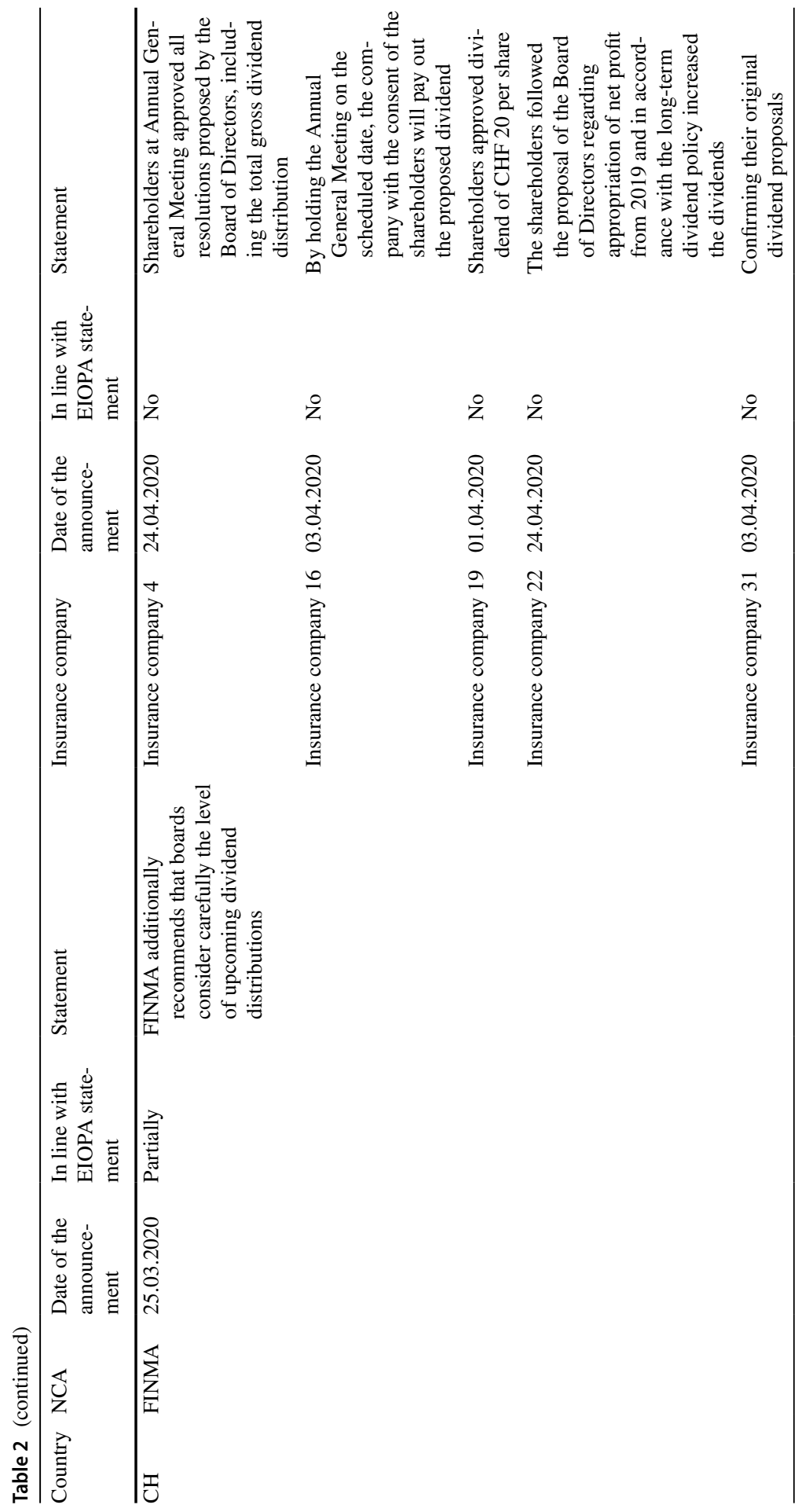




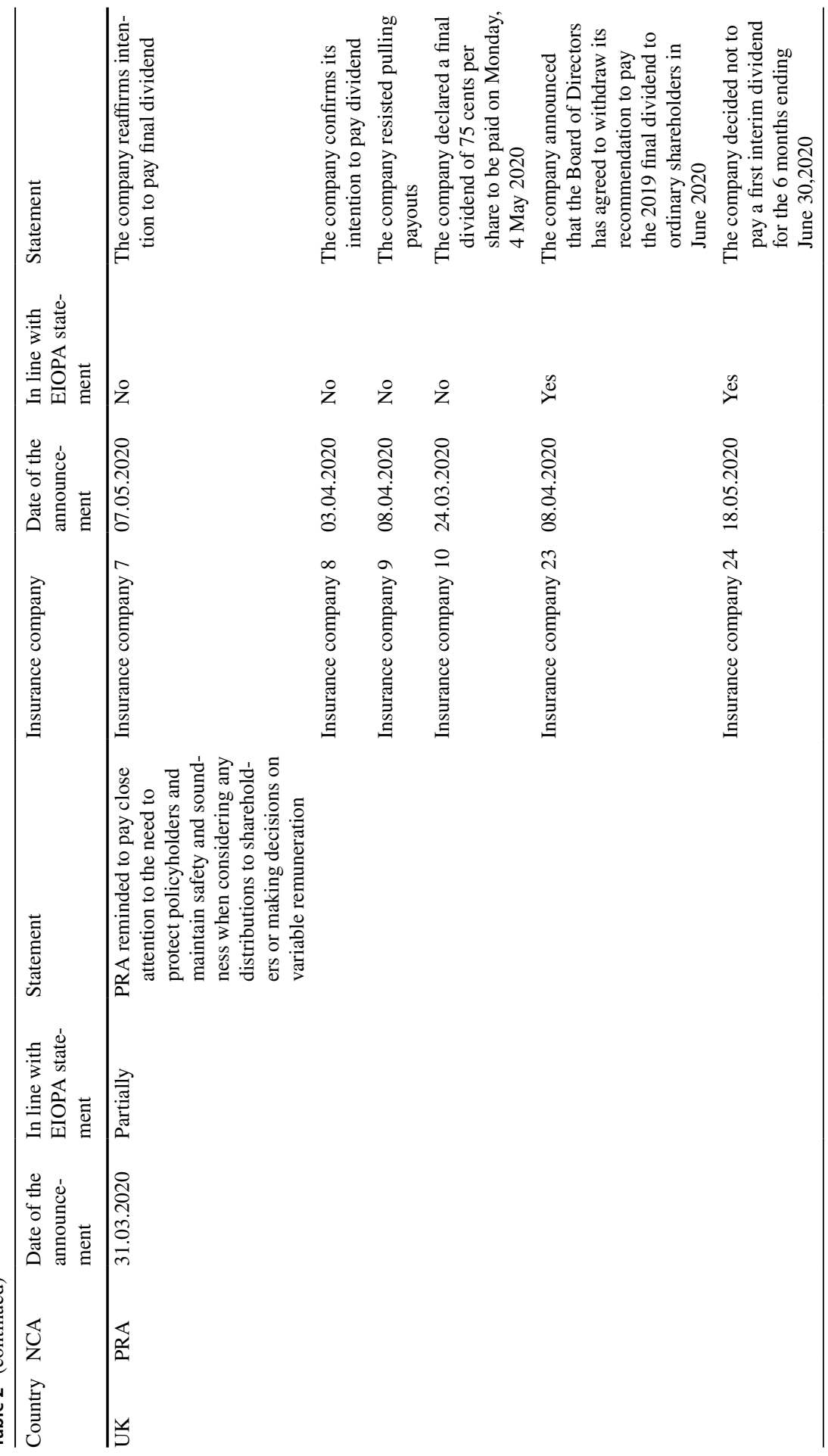

s. 


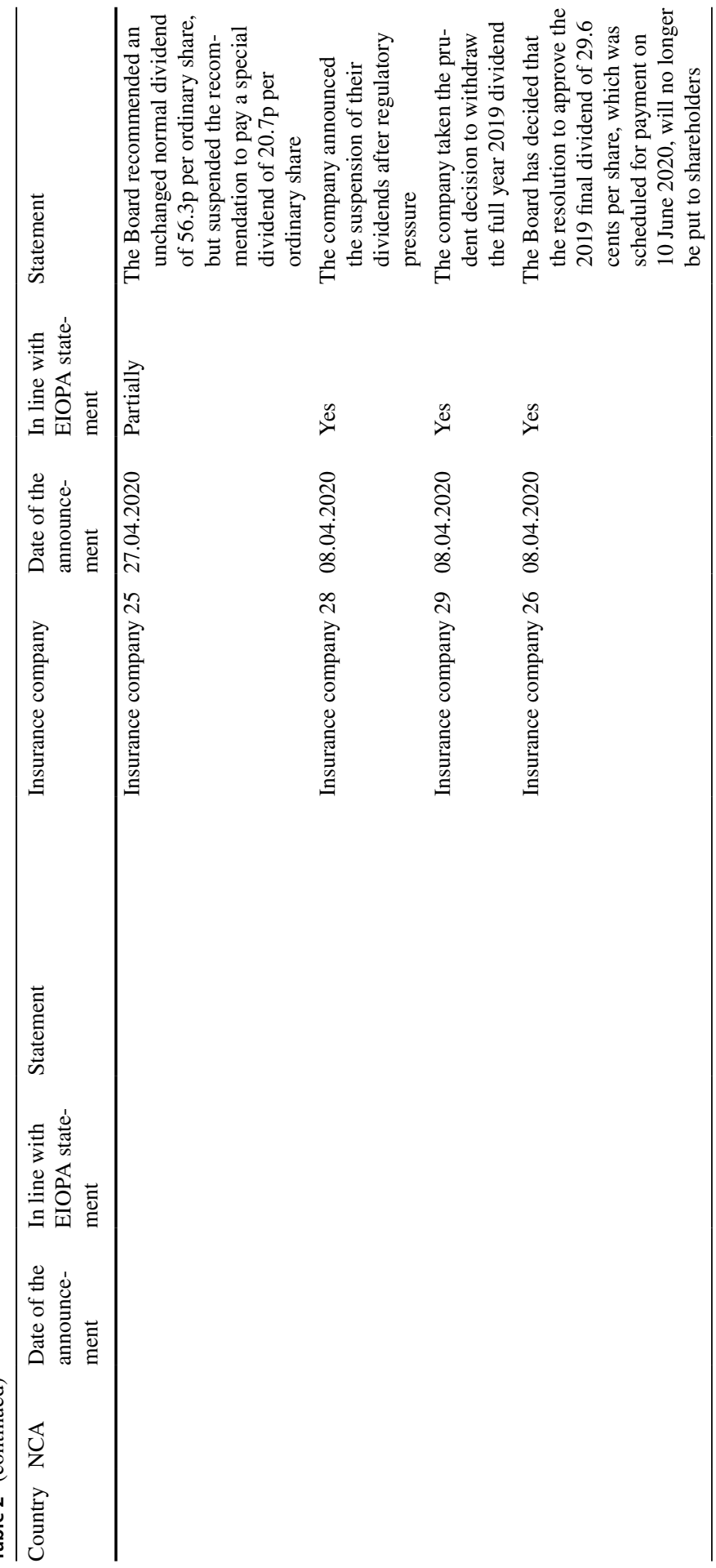




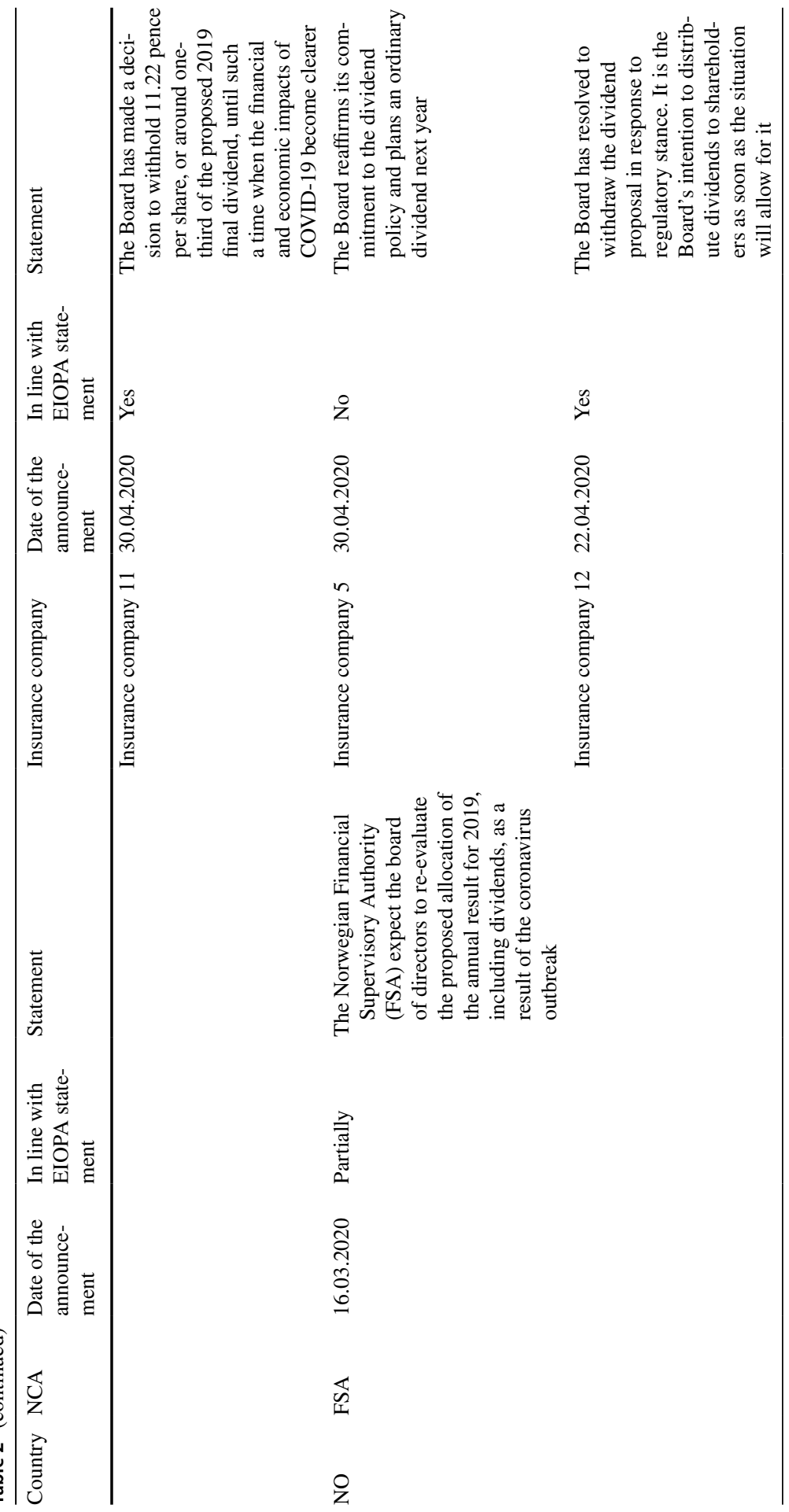

这称 


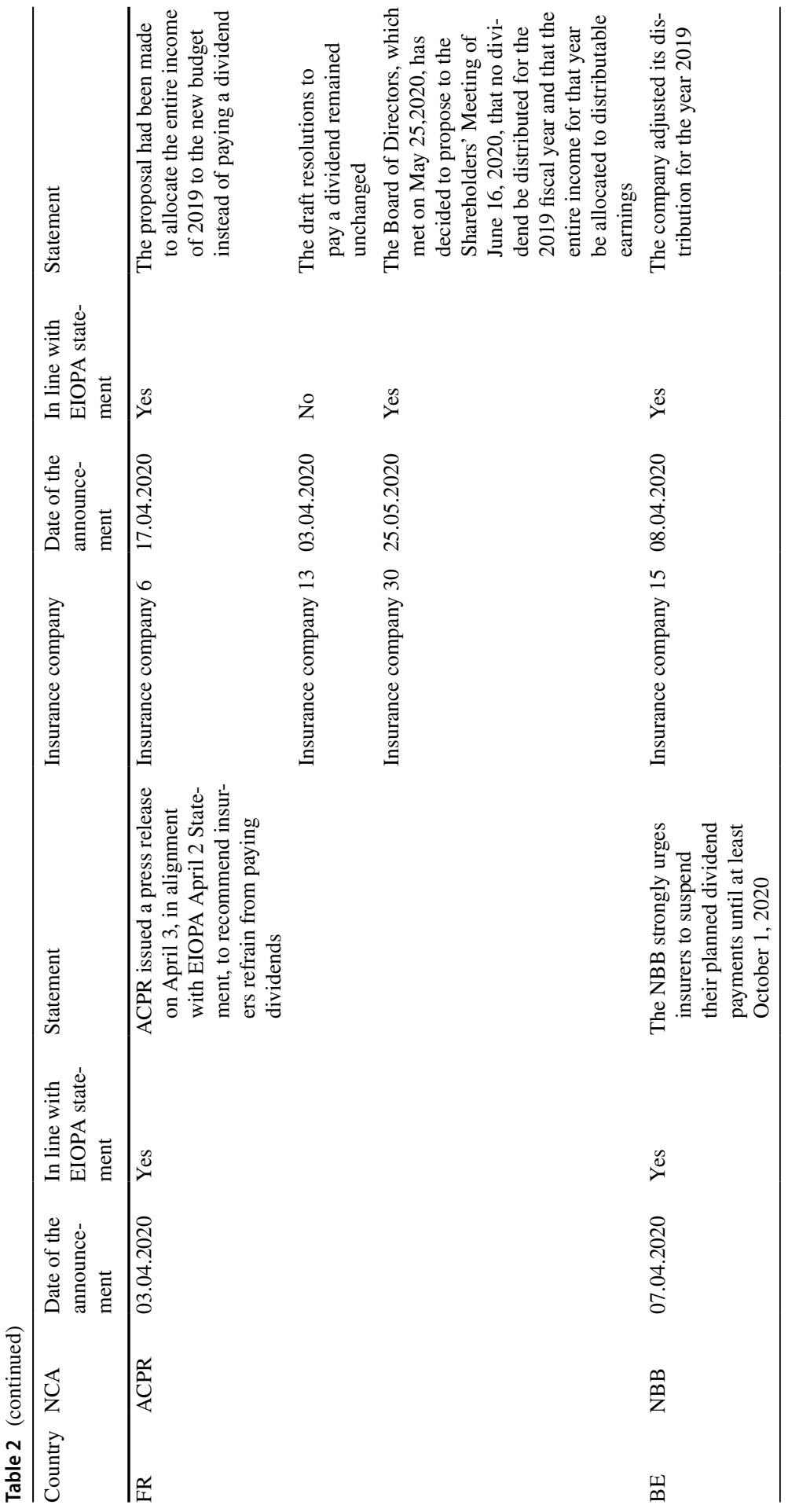




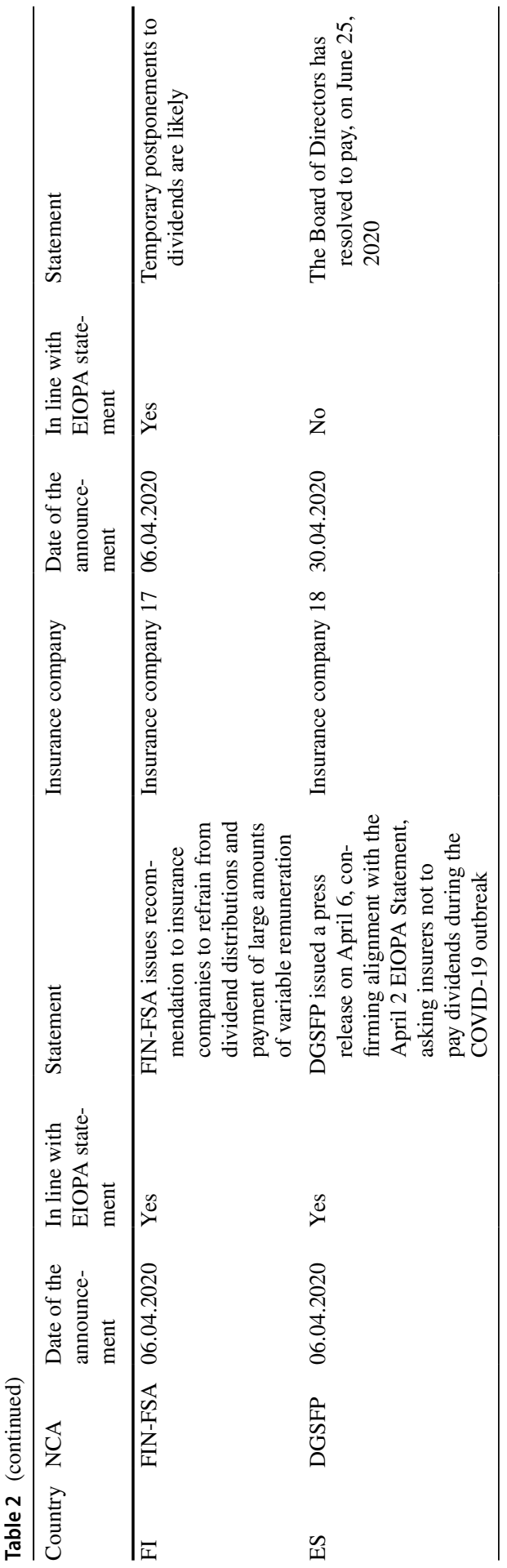

s. 


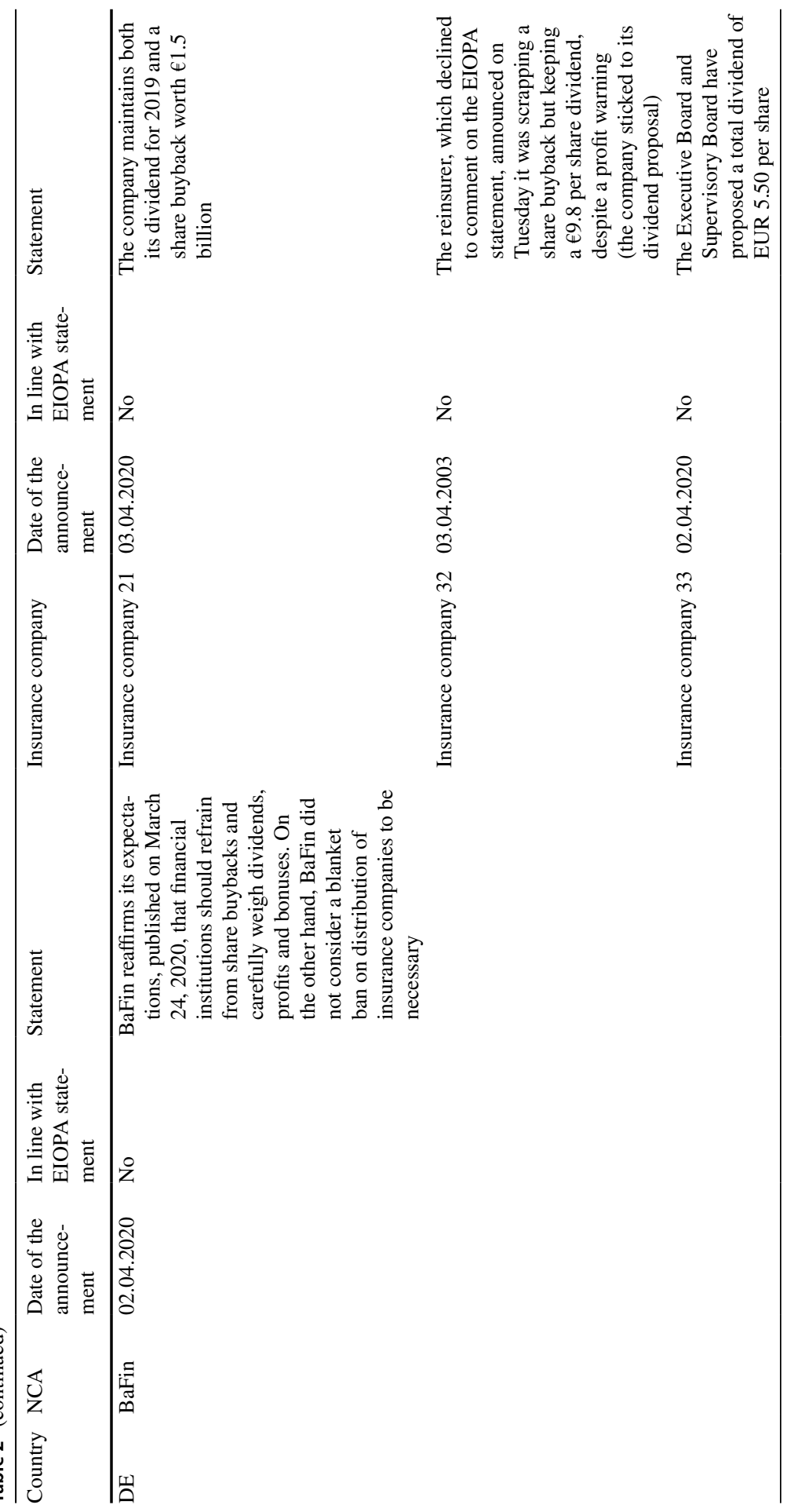




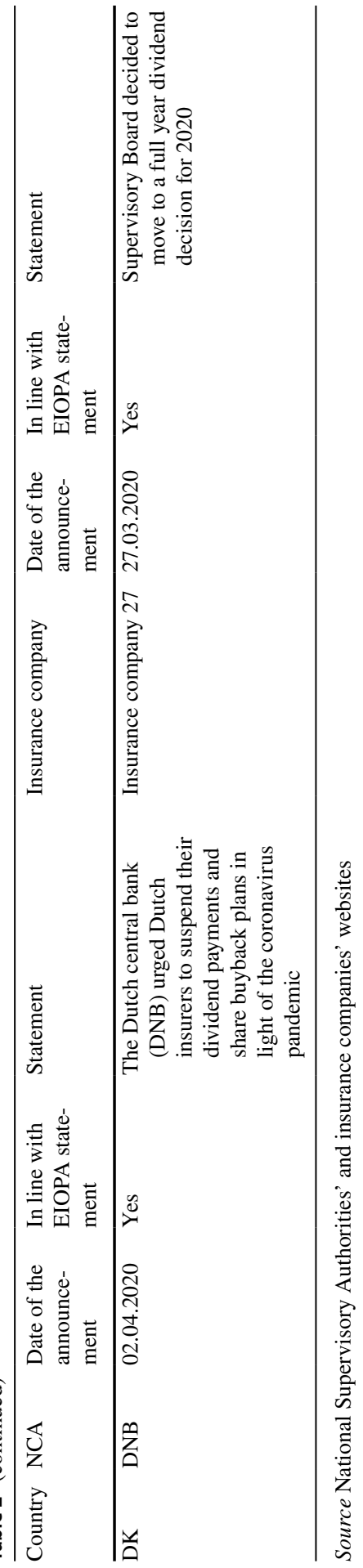

s. 


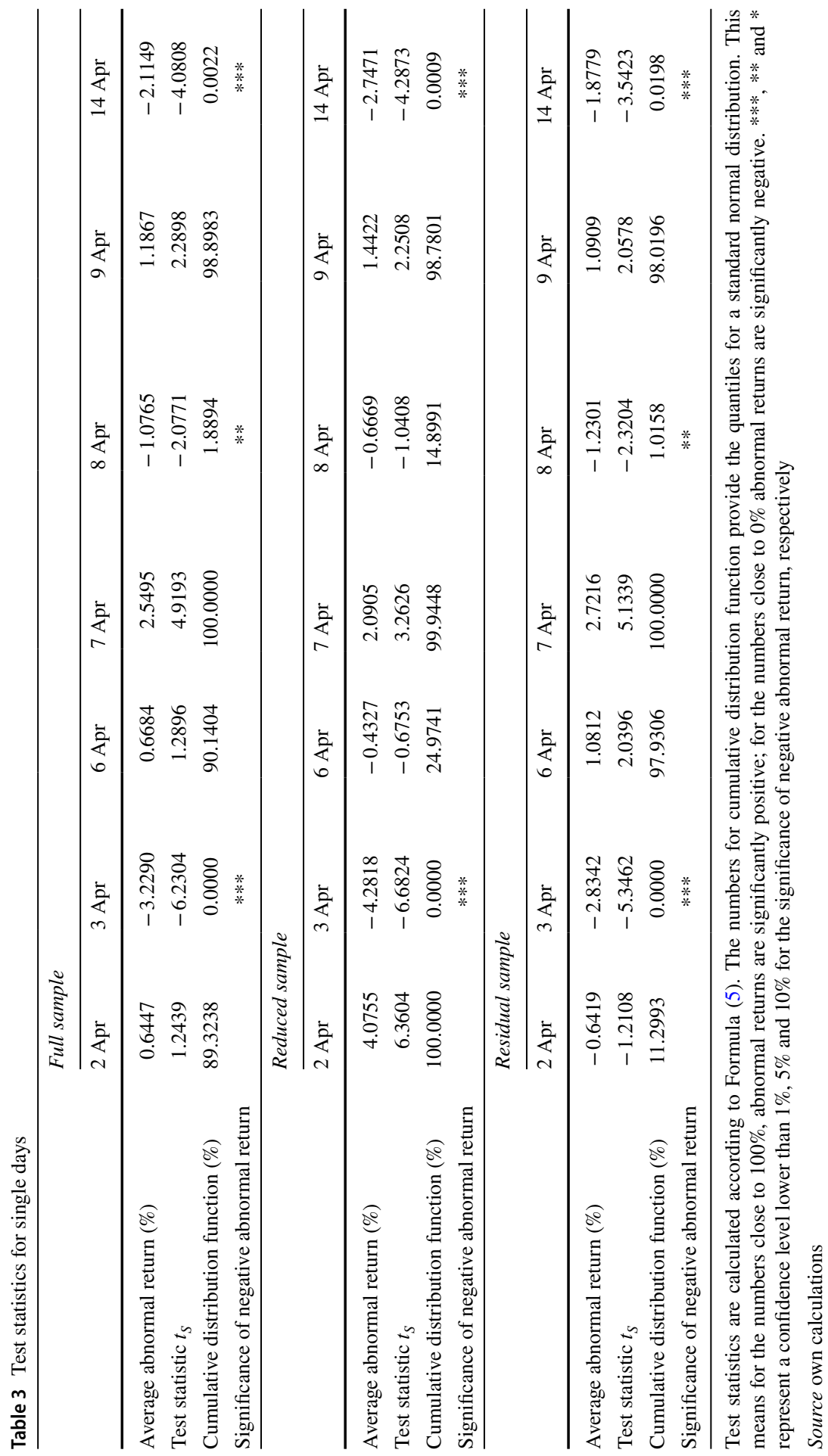




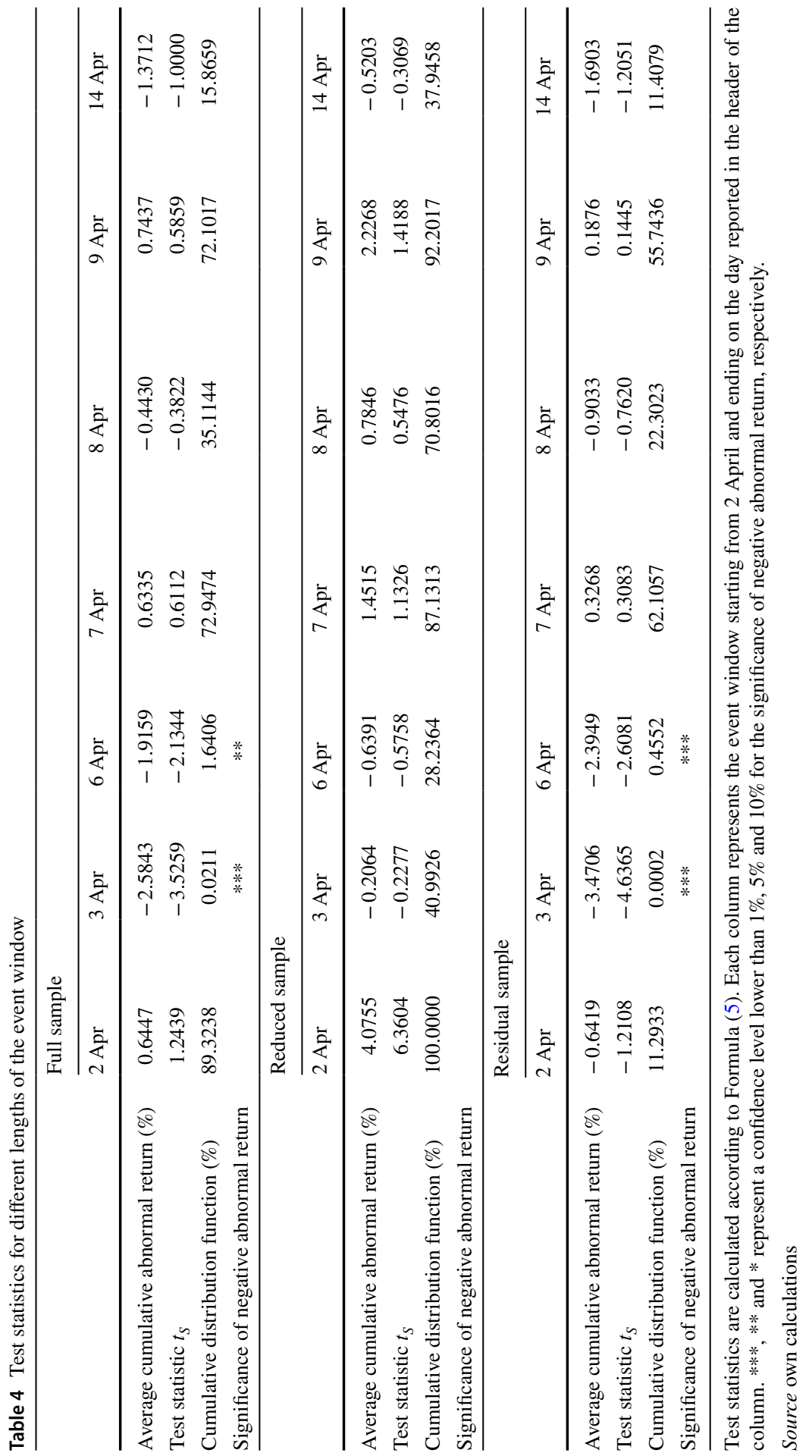




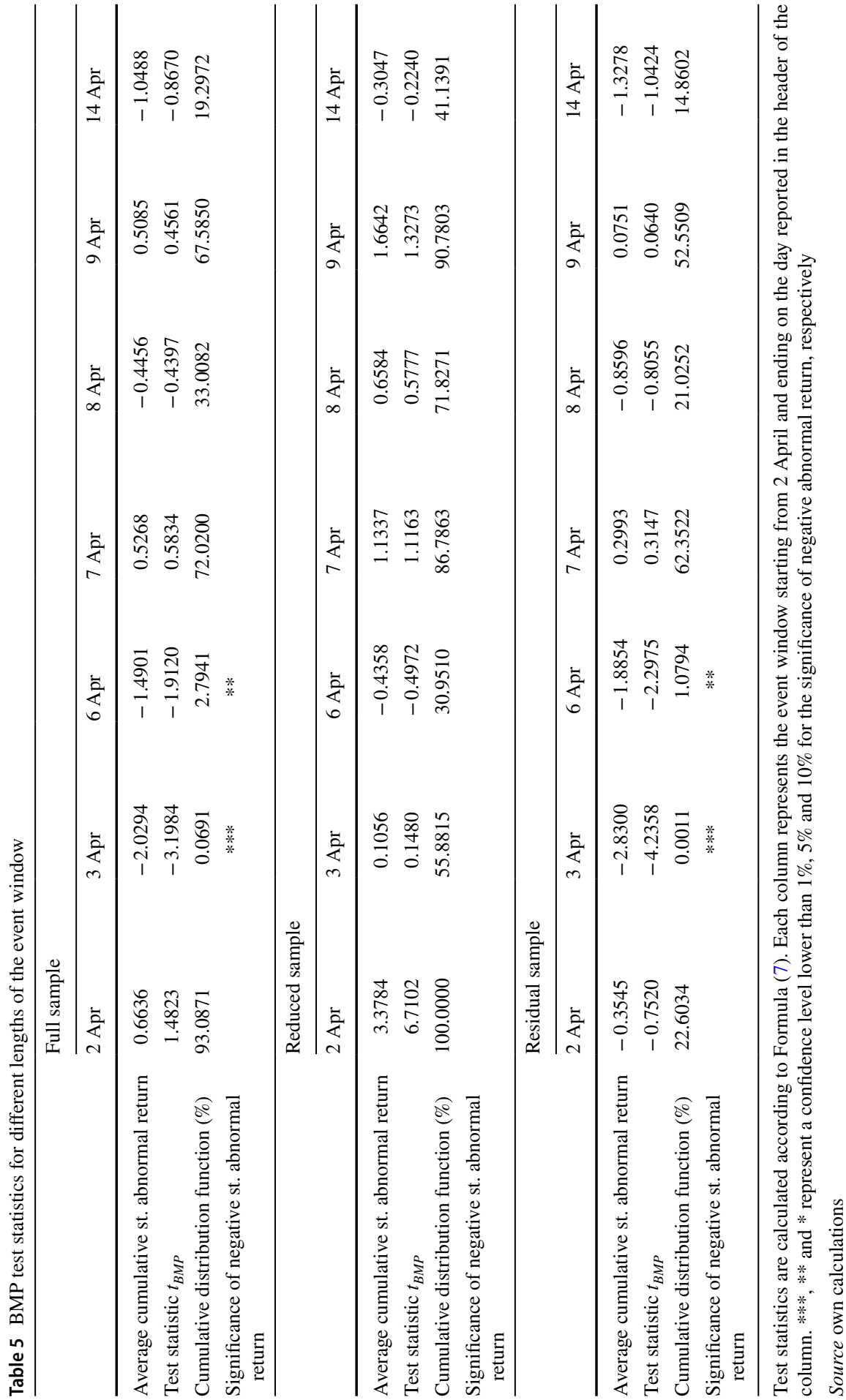




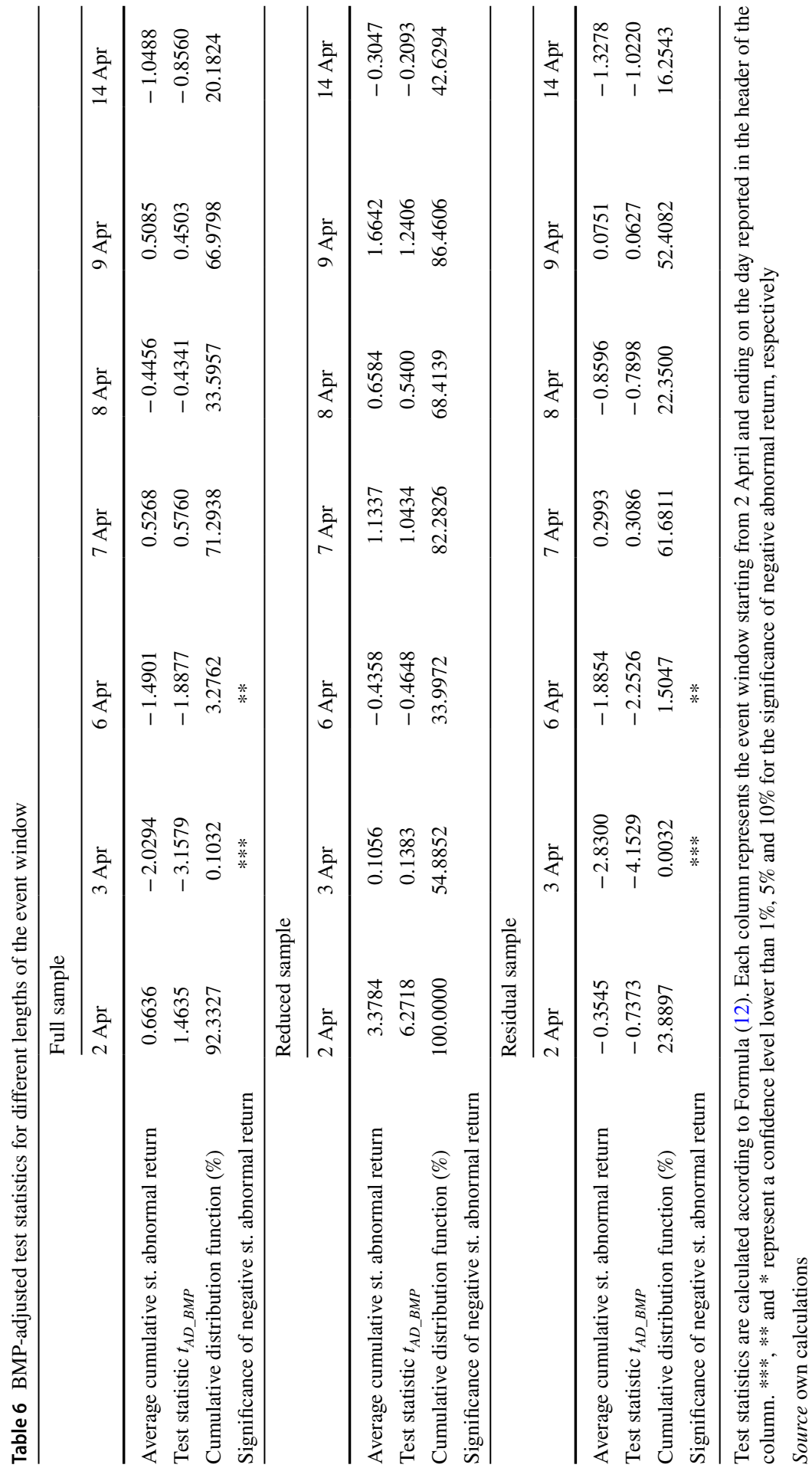




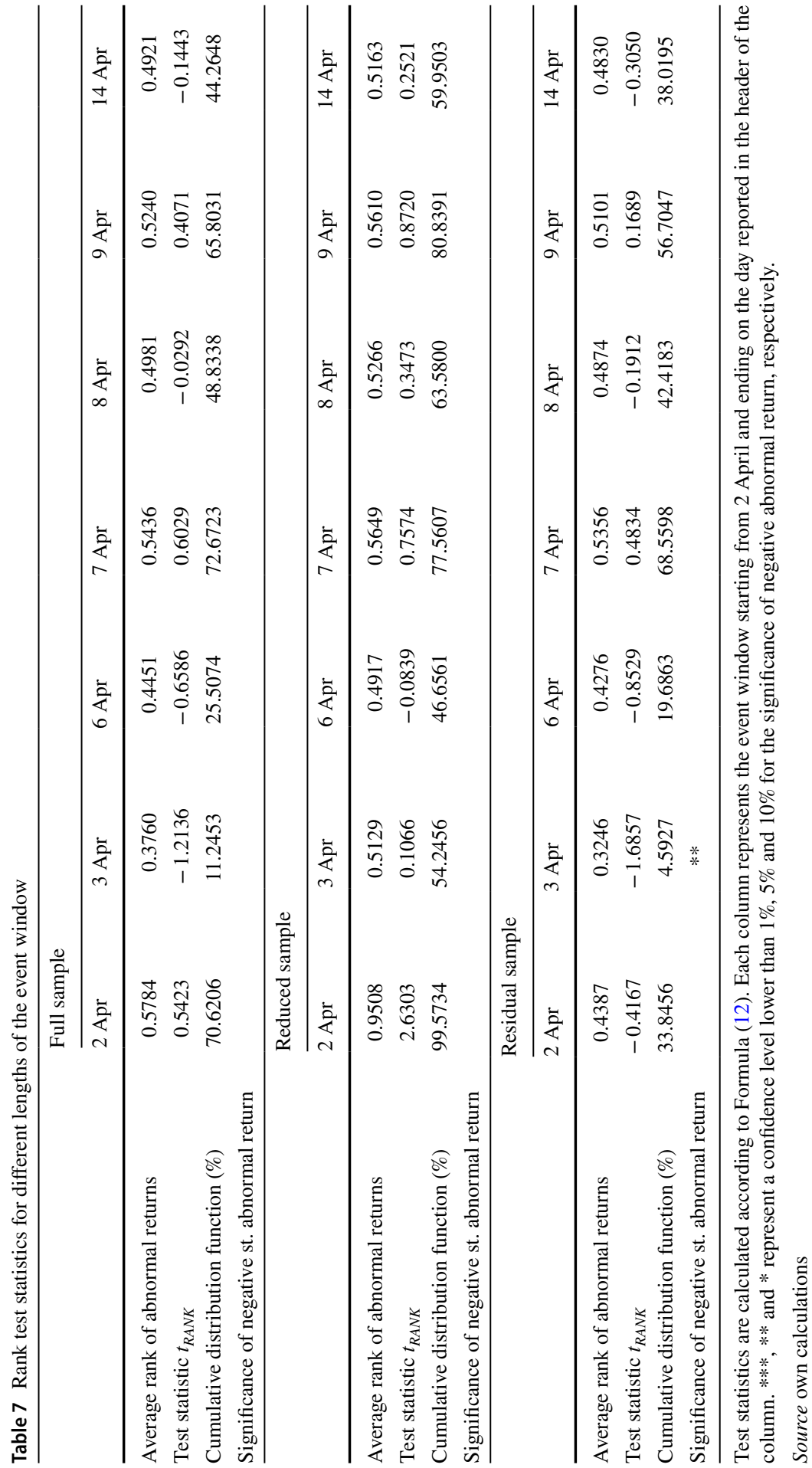


been falling heavily until mid-March but a strong recovery had begun at the end of March, reaching 2021 pre-crisis levels. However, given that, for all three samples tested, we could not reject the null hypothesis that the cumulative average abnormal returns are zero for three to seven days after the publication, we conclude that our findings are valid, also given the fact that the results for the reduced sample are even stronger.

\section{Conclusion}

This paper addresses the key issue of how NSAs, insurance companies and investors in the European Union responded to the EIOPA statement related to dividend payout suspension during the COVID-19 pandemic and resulting crisis. In line with the existing literature (e.g. Acharya et al. 2012), the aim of the EIOPA statement was to contribute to maintain the financial stability of the European insurance sector by recommending dividend restrictions, which would ensure sufficient capital during the crisis. A financially-sound European insurance sector could provide the necessary support for a rapid economic recovery through the provision of long-term funding and thus serve as a shock absorber.

On 2 April 2020, EIOPA urged that, during the coronavirus pandemic, re/insurers should temporarily suspend all discretionary dividend distributions and share buybacks aimed at remunerating shareholders, which was in line with research advocating regulatory restrictions in times of crisis (Acharya et al. 2012; Admati et al. 2013; Goodhart et al. 2010). Furthermore, NSAs issued their own statements that were broadly in line with that from EIOPA, with the exception of the German Supervisory Authority (BaFin). As a response to the EIOPA and national statements on dividend distributions, insurers issued their own announcements that were not always in line with the recommendation of supervisory authorities. This is because EIOPA and many NSAs do not have the legal power to force insurers to follow their recommendations. With the exception of several insurers based in Germany and Italy, the majority of insurance companies in Europe followed EIOPA's and their NSA's recommendations. All Swiss and some U.K. insurers (who are not members of EIOPA) paid out dividends, even though their national regulators had recommended a high level of prudency. The dividend policy of some Italian insurers seems to be in line with the findings of Reddemann et al. (2010): unlike other EMU insurers, dividend cuts or suspensions by Italian insurers may be interpreted as negative signals by investors and financial analysts.

Based on the event study methodology, our empirical results reveal that although a negative impact of the statement on insurers' equity was observed in some cases, it was not statistically significant for the European insurers' equity market overall. These results seem to be robust to different specifications using parametric tests such as BMP or adjusted BMP, as well as a non-parametric rank test. Generally, our results are in line with the existing literature, which suggests that dividend smoothing and dividend signalling are not relevant for the European insurance industry because agency theory might not hold for highly-regulated financial firms given that 
strong external monitoring is carried out by the regulators, in particular in times of crisis (Casey et al. 2009; Reddemann et al. 2010). This means that when cutting dividends, insurance companies do not need to fear negative consequences, such as costly external financing.

Hence, our paper suggests that the European insurance regulator might use dividend-based macroprudential measures to reduce agency costs. This would ensure sufficient solvency of the sector, avoid potential use of dividend signalling and smooth policies in times of crisis. Our empirical analysis further reveals that the EIOPA statement did not cause significantly greater volatility in the European insurance equity market.

Although we present short-term results, they reveal that investors and shareholders have trust in the European insurance market, and that insurers are perceived as solvent and prudent. Additionally, the drop in equity prices for some insurers for at least one day indicates that dividend smoothing or dividend signalling theory might be relevant for those particular insurers or the markets in which they operate. In this context, it would be interesting to further investigate the extent to which those drops are driven by an actual economic downturn, long-term dividend policies, the EIOPA statement, or country/insurer-specific factors. Our results also suggest that some NSAs might be aware not only of insurers' solvency positions, but also of the peculiarities of the dividend culture of their national insurance sector. From a theoretical perspective, the role of agency cost in a regulated market needs to be further investigated, particularly for an insurance sector where the monitoring function is not a critical one. Ultimately, further research needs to be conducted to investigate dividend distribution policies, taking into account different types of business models as well as the level of capital over the longer term.

\section{Appendix: Event study methodology}

Event studies assess the impact of the investigated event on equity prices by calculating their abnormal returns as the difference between the observed and expected returns. The observed daily logarithmic return of insurer $i$ at time $t$ is calculated as follows

$$
R_{i, t}=\ln \left(P_{i, t} / P_{i, t-1}\right)-1
$$

where $P_{i, t}$ is the equity closing price of insurer $i$ at time $t$.

The expected returns of insurers' equities are estimated via a simple ordinary least squares (OLS) regression employing the STOXX Europe 600 Index as a proxy for market return using daily data for the period prior to the event window, which we denote as $\left[T_{0}, T_{1}-1\right]$. Specifically, the period since the beginning of 2017 until 1 April 2020 was employed.

The abnormal return of insurer $i$ at time $t$ can be expressed as

$$
A R_{i, t}=R_{i, t}-\left(\alpha_{i}+\beta_{i} R_{m, t}\right)
$$


where $R_{m, t}$ is the daily logarithmic market return at time $t$ and $\alpha_{i}$ and $\beta_{i}$ (representing $\beta$ of insurer $i$ ) are the estimated parameters from an OLS regression.

Furthermore, the abnormal return observed through time and across the securities are aggregated. Given $n$ insurers, the cumulative average abnormal return for the event window is calculated as

$$
\overline{\mathrm{CAR}}=\sum_{t=T_{1}}^{T_{2}} A A R_{t},
$$

where

$$
A A R_{t}=\frac{1}{n} \sum_{i=1}^{n} A R_{i, t},
$$

where $T_{1}$ and $T_{2}$ represent the first and the last day of the considered event window.

The null hypothesis that the cumulative average abnormal returns are zero can be tested via the following test statistic

$$
t_{S}=\frac{\overline{\mathrm{CAR}}}{\sqrt{\operatorname{var}(\overline{\mathrm{CAR}})}},
$$

where the variance of abnormal cumulative returns can be calculated as

$$
\operatorname{var}(\overline{\mathrm{CAR}})=\operatorname{var}\left(A A R_{t}\right) L=\sigma^{2} L,
$$

where $L$ is the length of the event window and $\sigma^{2}$ corresponds to a standard error of the average abnormal return across all insurers estimated in the sample prior to the event window, corresponding to the interval $\left[T_{0}, T_{1}-1\right]$. The test statistics $t_{S}$ is asymptotically standard normal distributed under the null hypothesis.

However, $t$-tests can be prone to event-induced volatility. The test thus has a low power, particularly when samples feature non-normal returns, illiquidity or low prices (Brown and Warner 1985; Cambel and Wasley 1993; Kolari and Pynnonen 2010). Hence, we employ a standardised cross-sectional test (BMP test) proposed by Boehmer et al. (1991), which is robust to the variance induced by the event. The test statistics can be defined as

$$
t_{B M P}=\frac{\overline{\mathrm{SCAR}}}{\sqrt{\operatorname{var}(\overline{\mathrm{SCAR}})}},
$$

where

$$
\operatorname{var}(\overline{\mathrm{SCAR}})=\operatorname{var}\left(S A A R_{t}\right) L=\sigma_{s}^{2} L
$$




$$
\begin{gathered}
\overline{\mathrm{SCAR}}=\sum_{t=T_{1}}^{T_{2}} S A A R_{t}, \\
S A A R_{t}=\frac{1}{n} \sum_{i=1}^{n} S A R_{i, t}, \\
S A R_{i, t}=\frac{A R_{i, t}}{\sqrt{\operatorname{var}\left(A R_{i}\right)}},
\end{gathered}
$$

where $\sigma_{s}^{2}$ corresponds to a standard error of the average standardised abnormal return across all insurers estimated in the sample prior to the event window, corresponding to the interval $\left[T_{0}, T_{1-1}\right]$, and $\sqrt{\operatorname{var}\left(A R_{i}\right)}$ is a standard error of the abnormal return corresponding to a standard error of the model for expected market returns for insurer $i$ estimated by OLS regression.

The test statistic $t_{B M P}$ is asymptotically standard normal distributed under the null hypothesis.

The simulation study by Korali and Pynnonen (2010) indicates an over rejection of the null hypothesis in cases where cross-sectorial correlation is not considered. Hence, we implemented the adjusted version of BMP statistics, the socalled Adj-BMP test, to account for the cross-sectional correlation.

$$
t_{A D \_B M P}=t_{B M P} \sqrt{\frac{1-\bar{r}}{1+(n-1) \bar{r}}} .
$$

$\bar{r}$ is the average of the sample cross-correlations of the estimation period residual, corresponding to the period $\left[T_{0}, T_{1}-1\right]$.

The test statistic $t_{A D_{-} B M P}$ is asymptotically distributed as $N(0,1+(n-1) \bar{r})$ under the null hypothesis.

As a robustness check, we use the non-parametric rank test proposed by Corrado and Zivney (1992) for a single day and further elaborated by Cambel and Wasley (1993) for a multiday event period. In the first step, we transform abnormal returns into ranks. Ranking is done for all abnormal returns of both the event and estimation period. If ranks are tied, the mid-rank is used.

$$
K_{i, t}=\frac{\operatorname{rank}\left(A R_{i, t}\right)}{1+M+L} .
$$

$M$ is the number of observations in the estimation period $\left[T_{0}, T_{1}-1\right]$.

The null hypothesis that the cumulative average abnormal return is zero can be tested via the following test statistic: 


$$
t_{R A N K}=\sqrt{L} \frac{\bar{K}_{T_{1}, T_{2}}-0.5}{\sqrt{\operatorname{var}(\overline{\mathrm{K}})}},
$$

where $\operatorname{var}(\overline{\mathrm{K}})$ represents the variance of the average rank of abnormal returns estimated for both the estimated period and event window corresponding to the period $\left[T_{0}, T_{2}\right]$.

$$
\begin{gathered}
\bar{K}_{T_{1}, T_{2}}=\frac{1}{L} \sum_{t=T_{1}}^{T_{2}} \bar{K}_{t}, \\
\bar{K}_{t}=\frac{1}{n} \sum_{i=1}^{n} K_{i, t} .
\end{gathered}
$$

This test statistic $t_{R A N K}$ is asymptotically standard normal distributed under the null hypothesis.

Acknowledgements Financial support from the Czech Science Foundation (Project No. GA 20-00178S) is gratefully acknowledged. The views expressed in this paper are exclusively those of the authors and do not necessarily reflect those of the institutions with which the authors are affiliated.

\section{Declarations}

Conflict of interest On behalf of all authors, the corresponding author states that there is no conflict of interest.

\section{References}

Abreu, J.F., and M.A. Gulamhussen. 2013. Dividend payouts: Evidence from U.S. bank holding companies in the context of the financial crisis. Journal of Corporate Finance 22: 54-65.

Acharya, V., I. Gujral, N. Kulkarni, and H. Shin. 2012. Dividends and bank capital in the financial crisis of 2007-2009. NYU-Stern and Princeton University Working Paper.

Acharya, V., H.T. Le, and H. Shin. 2017. Bank capital and dividend externalities. Review of Financial Studies 30: 988-1018.

Admati, A., P. DeMarzo, M. Hellwig, and P. Páeiderer. 2013. Fallacies, irrelevant facts, and myths in the discussion of capital regulation: Why bank equity is not expensive. Stanford GSB Working Paper.

Akhigbe, A., S.F. Borde, and J. Madura. 1993. Dividend policy and signalling by insurance companies. Journal of Risk and Insurance 60: 413-425.

Almeida, H., M. Campello, and M.S. Weisbach. 2004. The cash flow sensitivity of cash. Journal of Finance 59: 1777-1804.

Bank for International Settlements. 2014. 84th Annual Report, 2013/14.

Black, F., and M. Scholes. 1974. The effects of dividend yield and dividend policy on common stock prices and returns. Journal of Financial Economics 1: 1-22.

Boehmer, E., J. Masumeci, and A.B. Poulsen. 1991. Event-study methodology under conditions of eventinduced variance. Journal of Financial Economics 30 (2): 253-272.

Brown, S.J., and J.B. Warner. 1985. Using daily stock returns: The case of event studies. Journal of Financial Economics 14 (1): 3-31.

Browne, M.J., J.M. Carson, and R.E. Hoyt. 1999. Economic and market predictors of insolvencies in the life-health insurance industry. Journal of Risk and Insurance 66 (4): 643-659. 
Brunnermeier, M., et al. 2009. The fundamental principles of financial regulation. Geneva Reports on the World Economy 11.

Cambel, C.J., and C.E. Wesley. 1993. Measuring security price performance using daily NASDAQ returns. Journal of Financial Economics 33 (1): 73-92.

Casey, K.M., F.S. Smith, and V.A. Puleo. 2007. Dividend policy determinants in the insurance industry. Journal of Academy of Business and Economics 7: 178-184.

Casey, K.M., F.S. Smith, and V.A. Puleo. 2009. Insurance company dividend policy decisions-Evidence on the role of corporate governance and regulation. Managerial Finance 35: 493-500.

Corrado, C.J., and T.L. Zivney. 1992. The specification and power of the sign test in event study hypothesis tests using daily stock returns. Journal of Financial and Quantitative Analysis 27 (3): 465-478.

David, T., and E. Ginglinger. 2016. When cutting dividends is not bad news: The case of optional stock dividends. Journal of Corporate Finance 40 (October): 174-191.

DeAngelo, H., L. DeAngelo, and D.J. Skinner. 2009. Corporate payout policy. Foundations and Trends in Finance 3 (23): 95-287.

Docking, S., and P. Koch. 2005. Sensitivity of investor reaction to market direction and volatility: Dividend change announcements. Journal of Financial Research 28 (1): 21-40.

EIOPA. 2018. Failures and near misses in insurance. Publications Office of the European Union.

EIOPA. 2020. EIOPA statement on dividends distribution and variable remuneration policies in the context of COVID-19.

Faccio, M., L. Lang, and L. Young. 2001. Dividends and expropriation. American Economic Review 91: 54-78.

Gallo, L.A., R.N. Hann, and C. Li. 2016. Aggregate earnings surprises, monetary policy, and stock returns. Journal of Accounting and Economics 62 (1): 103-120.

Goodhart, C.A., E.U. Peiris, D. Tsomocos, and A. Vardoulakis. 2010. On dividend restrictions and the collapse of the interbank market. Annals of Finance 6 (4): 455-473.

Grace, M.F., R.W. Klein, and R.D. Phillips. 2003. Insurance company failures: Why do they cost so much? Georgia State University Center for Risk Management and Insurance Research Working Paper No. 03-1.

Gupta, N.J., V. Strohush, and R. White. 2019. Investor reaction to simultaneous news releases: Unemployment vs. earnings. Journal of Economics and Finance 43: 735-749. https://doi.org/10.1007/ s12197-018-9460-z.

Harrington, S.E. 1981. Stock life insurer shareholder dividend policy and holding company affiliation. Journal of Risk and Insurance 48: 550-576.

Jenden, M.C., and W.H. Meckling. 1976. Theory of the firm: Managerial behaviour, agency costs and ownership structure. Journal of Financial Economics 3 (4): 305-360.

Jeong, J. 2013. Determinants of dividend smoothing in emerging market: The case of Korea. Emerging Markets Review 17: 76-88.

Kim, C. 2005. Modeling surrender and lapse rates with economic variables. North American Actuarial Journal 9 (4): 56-70.

Kolari, J.W., and S. Pynnonen. 2010. Event study testing with cross-sectional correlation of abnormal returns. Review of Financial Studies 23 (11): 3996-4025.

La Porta, R., F. Lopez-de-Silane, A. Shleifer, and R. Vishny. 1998. Agency problems and dividend policies around the world. NBER Working Paper No. 6594.

Leary, M.T., and R. Michaely. 2011. Determinants of dividend smoothing: Empirical evidence. Review of Financial Studies 24 (10): 3197-3249.

Lee, C.F., and S.W. Forbes. 1980. Dividend policy, equity value, and cost of capital estimates in the property and liability insurance industry. Journal of Risk and Insurance 47: 205-222.

Liedtke, P.M. 2021. Vulnerabilities and resilience in insurance investing: Studying the COVID-19 pandemic. The Geneva Papers on Risk and Insurance: Issues and Practice 46: 266-280.

Lintner, J. 1956. Distribution of incomes of corporations among dividends, retained earnings, and taxes. American Economic Review 46: 97-113.

MacKinlay, A.C. 1997. Event studies in economics and finance. Journal of Economic Literature 35 (1): 13-39.

Modigliani, F., and M. Miller. 1959. The cost of capital, corporation finance, and the theory of investment: Reply. American Economic Review 49: 655-669.

Rozeff, M.S. 1982. Growth, beta, and agency costs as determinants of dividend payout ratios. The Journal of Financial Research 5: 249-259. 
Shin, H.S. 2016. Bank capital and monetary policy transmission. In The ECB and its Watchers XVII conference, Frankfurt, 7 April 2016.

The Geneva Association. 2012. Surrenders in the life insurance industry and their impact on liquidity. Authors: Daniel Haefeli and Wilhelm Ruprecht. August.

Thompson, R. 1995. Empirical methods of event studies in corporate finance. In Handbook in operations research and management science. Amsterdam: Elsevier.

Tomuleasa, I.I. 2015. Central bank communication and its role in ensuring financial stability. Procedia Economics and Finance 20: 637-644.

Publisher's Note Springer Nature remains neutral with regard to jurisdictional claims in published maps and institutional affiliations.

\section{About the authors}

Petr Jakubik leads the Financial Stability Team at the European Insurance and Occupational Pensions Authority (EIOPA) responsible for financial stability analyses and assessments including insurance and pension EU-wide stress tests, financial stability reports, risk dashboards and research. Previously, he worked as an principal expert at EIOPA, economist at the European Central Bank, technical adviser at the Bank for International Settlements, financial stability consultant at the Oesterreichische Nationalbank and Central Bank of Malta, chief economist at the Czech National Bank, visiting researcher at the Bank of Finland and scoring expert in the private banking sector. He received the Financial Stability Institute Award 2008 and Irving Fisher Committee Award 2010 of the Bank for International Settlements. In 2012-2013, he was the President of the Czech Economic Society. He provided extensive technical assistance in the area of financial stability, designed macro stress tests for the Central Bank of the Republic of Turkey, National Bank of Serbia and Central Bank of Malta. He regularly gives trainings and presentations on financial stability issues in different international fora, having sound policy-relevant publication record. In 2015, he was habilitated as an associate professor in economic theories by the Charles University. He lectures at the Charles University and the University of Finance and Administration in Prague. He holds two doctorate degrees in finance and economics, three master degrees in economics, statistics \& insurance mathematics, and mathematics \& computer sciences.

Saida Teleu works as a senior economist in the Central Bank of Malta responsible for financial stability analyses and assessment including risk modelling, stress testing, and economic research. Previously, she worked as an analyst at the Single Supervisory Mechanism, European Central Bank. During this time she was also assigned to work at the Oesterreichische Nationalbank. She holds a doctorate degree in economic policies and a master degree in international economic relations from the University of Economics in Prague. Currently, she is pursuing her second Ph.D. in economics \& finance at Charles University in Prague. 